\title{
Dual inhibition of survivin and MAOA synergistically impairs growth of PTEN-negative prostate cancer
}

\author{
$\mathrm{S} \mathrm{Xu}{ }^{1}, \mathrm{H}$ Adisetiyo ${ }^{2}$, S Tamura ${ }^{1}$, F Grande ${ }^{3}$, A Garofalo ${ }^{3}$, P Roy-Burman ${ }^{2}$ and N Neamati ${ }^{*}, 1$
}

${ }^{1}$ Department of Medicinal Chemistry, College of Pharmacy, Translational Oncology Program, University of Michigan, Ann Arbor, MI 48109, USA; ${ }^{2}$ Department of Pathology, Keck School of Medicine, University of Southern California, Los Angeles, CA 90033, USA and ${ }^{3}$ Dipartimento di Farmacia e Scienze della Salute e della Nutrizione, Università della Calabria, Arcavacata di Rende, Italy

Background: Survivin and monoamine oxidase A (MAOA) levels are elevated in prostate cancer (PCa) compared to normal prostate glands. However, the relationship between survivin and MAOA in PCa is unclear.

Methods: We examined MAOA expression in the prostate lobes of a conditional PTEN-deficient mouse model mirroring human $\mathrm{PCa}$, with or without survivin knockout. We also silenced one gene at a time and examined the expression of the other. We further evaluated the combination of MAOA inhibitors and survivin suppressants on the growth, viability, migration and invasion of PCa cells.

Results: Survivin and MAOA levels are both increased in clinical PCa tissues and significantly associated with patients' survival. Survivin depletion delayed MAOA increase during PCa progression, and silencing MAOA decreased survivin expression. The combination of MAOA inhibitors and the survivin suppressants (YM155 and SC144) showed significant synergy on the inhibition of PCa cell growth, migration and invasion with concomitant decrease in survivin and MMP-9 levels.

Conclusions: There is a positive feedback loop between survivin and MAOA expression in PCa. Considering that survivin suppressants and MAOA inhibitors are currently available in clinical trials and clinical use, their synergistic effects in PCa support a rapid translation of this combination to clinical practice.

Prostate cancer (PCa) is the most commonly diagnosed and the second most lethal cancer among men in the United States. Resistance to androgen ablation and docetaxel (DTX) chemotherapy usually result in cancer recurrence and death of patients. Therefore, novel therapeutic strategies are in urgent medical need.

Encoded by the BIRC5 gene, survivin is a member of the inhibitor of apoptosis protein (IAP) family. As a promising drug target, survivin is highly expressed in most tumours and fetal tissues (Velculescu et al, 1999) but is absent in almost all terminally differentiated cells (Sah et al, 2006). Survivin is a nodal protein regulating multiple cellular pathways that mediate tumourigenesis, including the suppression of apoptosis, the promotion of chromosome segregation and the upregulation of tumour vasculature (Church and Talbot, 2012; Debnath et al, 2012). Expression of survivin in PCa contributes to chemoresistance and cancer progression (Altieri, 2008; Altieri et al, 2009; Adisetiyo et al, 2013). Although inhibiting survivin will be a promising approach in treating $\mathrm{PCa}$, currently there are only a limited number of selective inhibitors including the BIRC5 transcription suppressant YM155 (Nakahara et al, 2007) and the survivin dimerisation modulator Abbott8 (Wendt et al, 2007). YM155 exhibited potency in in vitro and in vivo PCa models (Nakahara et al, 2007), and it is currently in phase II clinical trials for PCa as a single agent and in combination with DTX (Tolcher et al, 2012). Previously, we discovered novel quinoxalinhydrazides with desirable physicochemical and drug-like 
properties and a broad-spectrum anticancer activity (Grande et al, 2007, 2009; Oshima et al, 2009). Our lead compound, SC144, is a potent survivin suppressant through the inhibition of the IL-6/gp130/Stat3 signalling axis (Xu and Neamati, 2013; Xu et al, 2013a). Although YM155 and SC144 have unique mechanisms of action, they both ultimately suppress survivin expression and can be used as tools to unravel the biology of survivin.

Monoamine oxidase A (MAOA) is a mitochondrial enzyme that degrades amine neurotransmitters, such as 5-hydroxytryptamine (5-HT), norepinephrine, epinephrine and dopamine (Shih et al, 1999). Therefore, MAOA has been extensively studied in neurological disorders, such as Parkinson's disease and depression (Youdim et al, 2006). Interestingly, an increase in the number of 5-HT-releasing neuroendocrine cells has been correlated with tumour progression, and 5-HT serves as a growth factor for PCa cells (Shinka et al, 2011). In addition, elevated expression of MAOA correlates with high-grade $\mathrm{PCa}$, and contributes to its poorly differentiated phenotype (Vaarala et al, 2000; True et al, 2006; Peehl et al, 2008; Zhao et al, 2008). Moreover, a polymorphism of the MAOA promoter that confers low-MAOA expression was associated with a reduced risk of PCa (White et al, 2012). Although the molecular mechanisms and functions of MAOA in PCa are not clear, amine metabolism is associated with cellular processes including cell growth and differentiation (Pietrangeli and Mondovi, 2004). Substitutions of aspartic acid residues in MAOA affected cell viability and proliferation (Wei et al, 2012). Clorgyline, a selective and irreversible MAOA inhibitor previously used as an anti-depression medicine, showed efficacy in in vitro and in vivo PCa models (Zhao et al, 2009; Flamand et al, 2010). Another MAOA inhibitor, phenelzine sulphate, combined with DTX is currently under phase II clinical trials for PCa patients with progressive disease.

Using a PTEN ${ }^{-1-}$ mouse model and human PCa cell lines, we have demonstrated for the first time that MAOA expression is regulated by the PTEN/Akt pathway and influenced by survivin. By using SC144 or YM155 in combination with clorgyline, we unravelled a novel synergy between survivin and MAOA dual inhibition for the treatment of PTEN-negative PCa. Considering the availability of inhibitors of survivin (YM155, EM-1421, LY2181308 and EZN-3042) and MAOA (phenelzine, tranylcypromine, isocarboxazid and moclobemide) in clinical trials or clinical use, our finding supports a novel chemotherapeutic regimen for the treatment of PTEN-negative PCa with high survivin/MAOA levels.

\section{MATERIALS AND METHODS}

Cell lines. LNCaP cells were kindly provided by Dr Alan L Epstein (University of Southern California). PC3, DU145 and C4-2B cell lines were kindly provided by Dr Shigang Xiong (University of Southern California). Mouse PCa cells CE1, CE2, E2, E4 and E8 were generated by Dr Pradip Roy-Burman (University of Southern California).

Mouse prostate gland and prostate tumour tissues. Prostate gland and prostate tumour tissues from mice with conditional Pten deletion were homogenised. All the experiments have been carried out with ethical committee approval and meet the standards required by the UKCCCR guidelines (Workman et al, 2010).

Growth inhibition assay. Growth inhibition was assessed using a 3-(4,5-dimethylthiazol-2-yl)-2,5-diphenyltetrazolium bromide (MTT) assay as described in Zeng et al (2012) and Saha et al (2013). Cells were seeded in 96-well plates and treated with indicated drugs for $72 \mathrm{~h}$. After drug treatments, cells were incubated with MTT $\left(0.3 \mathrm{mg} \mathrm{ml}^{-1}\right)$ for additional $3 \mathrm{~h}$ at $37^{\circ} \mathrm{C}$. After removal of the supernatant, DMSO was added and the absorbance was measured at $570 \mathrm{~nm}$. All assays were performed in triplicate. Inhibitory concentration $50 \%\left(\mathrm{IC}_{50}\right)$ values were determined from a plot of $\log$ (drug concentration) vs percentage of cell kill, using Prism 6 (GraphPad Software, Inc., La Jolla, CA, USA).

Colony formation assay. Colony formation assays were performed as described in Xu et al (2012). Briefly, cells (200 cells per well) were seeded in 96-well plates, followed by the incubation of indicated compounds for $48 \mathrm{~h}$, and then were allowed to grow into colonies in the absence of compound treatment (12-15 days). Colonies were stained with crystal violet solution (2\%).

Cell migration assay. Twenty-four-well plates were precoated with collagen $\left(45 \mu \mathrm{g} \mathrm{ml}^{-1}\right)$ in triplicates, followed by further BSA $\left(2 \mathrm{mg} \mathrm{ml}^{-1}\right.$ ) blocking. Serum-starved cells were plated (350000 cells per well) $2 \mathrm{~h}$ before scratches were made using $200 \mu \mathrm{l}$ pipette tips. Floating cells were removed by PBS washing, followed by the addition of media with $10 \%$ FBS and indicated compounds. Images were taken after $48 \mathrm{~h}$.

Western blotting. Western blotting was performed as previously described (Xu et al, 2013b). Proteins in whole-cell lysates were resolved in SDS-PAGE and electrotransferred onto Hybond-P (GE Healthcare, Wauwatosa, WI, USA) membrane. The membrane was then probed with indicated primary antibodies, subsequently with infrared fluorescence dye-conjugated secondary antibodies and scanned and analysed using the Odyssey CLx Imaging system (LI-COR, Inc., Lincoln, NE, USA).

Immunohistochemical analysis. As previously described (Yamada et al, 2010), paraffin-embedded prostate tissue sections were deparaffinised and rehydrated and then subjected to antigen retrieval in $10 \mathrm{~mm}$ sodium citrate buffer at $95^{\circ} \mathrm{C}$. Slides were then incubated in $1 \% \mathrm{H}_{2} \mathrm{O}_{2}$ in methanol to block the endogenous peroxidase activity. Sections were blocked with $10 \%$ normal goat serum (Vector Laboratories, Burlingame, CA, USA) and $0.3 \%$ Triton X-100 (Fisher Scientific, Pittsburgh, PA, USA) in TBS for $1 \mathrm{~h}$ at room temperature and incubated in survivin antibody overnight at $4{ }^{\circ} \mathrm{C}$. The next day, affinity-purified, biotinylated goat anti-rabbit IgG $(\mathrm{H}+\mathrm{L})$ secondary antibody (Vector Laboratories) was added to the sections and the staining was visualised with detection reagents: VECTASTAIN Elite ABC kit (Vector Laboratories) and DAB (DAKO, Carpinteria, CA, USA). The slides were counterstained with haematoxylin (Sigma-Aldrich, St Louis, MO, USA), rinsed and dehydrated before cover slips were placed over the tissue.

Statistical analysis. The Student's $t$-test was used for statistical analysis and $P$-value determination using Prism 6 (GraphPad, Inc.). Differences were considered statistically significant at $P<0.05$.

\section{RESULTS}

Survivin protein level is upregulated in the PTEN-negative PCa model. Up to $70 \%$ of PCa patients have lost one copy of the Pten gene at the time of diagnosis (Gray et al, 1998) associated with aggressive metastatic potential, poor prognosis and androgen independence (Trotman et al, 2003). Our mouse PCa model has conditional homozygous deletion of PTEN in the prostate gland leading to spontaneous PCa development (Wang et al, 2003). Recently, we have shown that survivin deletion has no effect on normal prostate development but reduced the appearance of prostatic intraepithelial neoplasia and hampered the progression to adenocarcinoma (Adisetiyo et al, 2013). In addition, we have generated a prostate-specific Pten and Survivin double-knockout mouse strain. Survivin expression was observed mostly in the epithelial cells of the mouse prostate, and increased in the prostate 
A
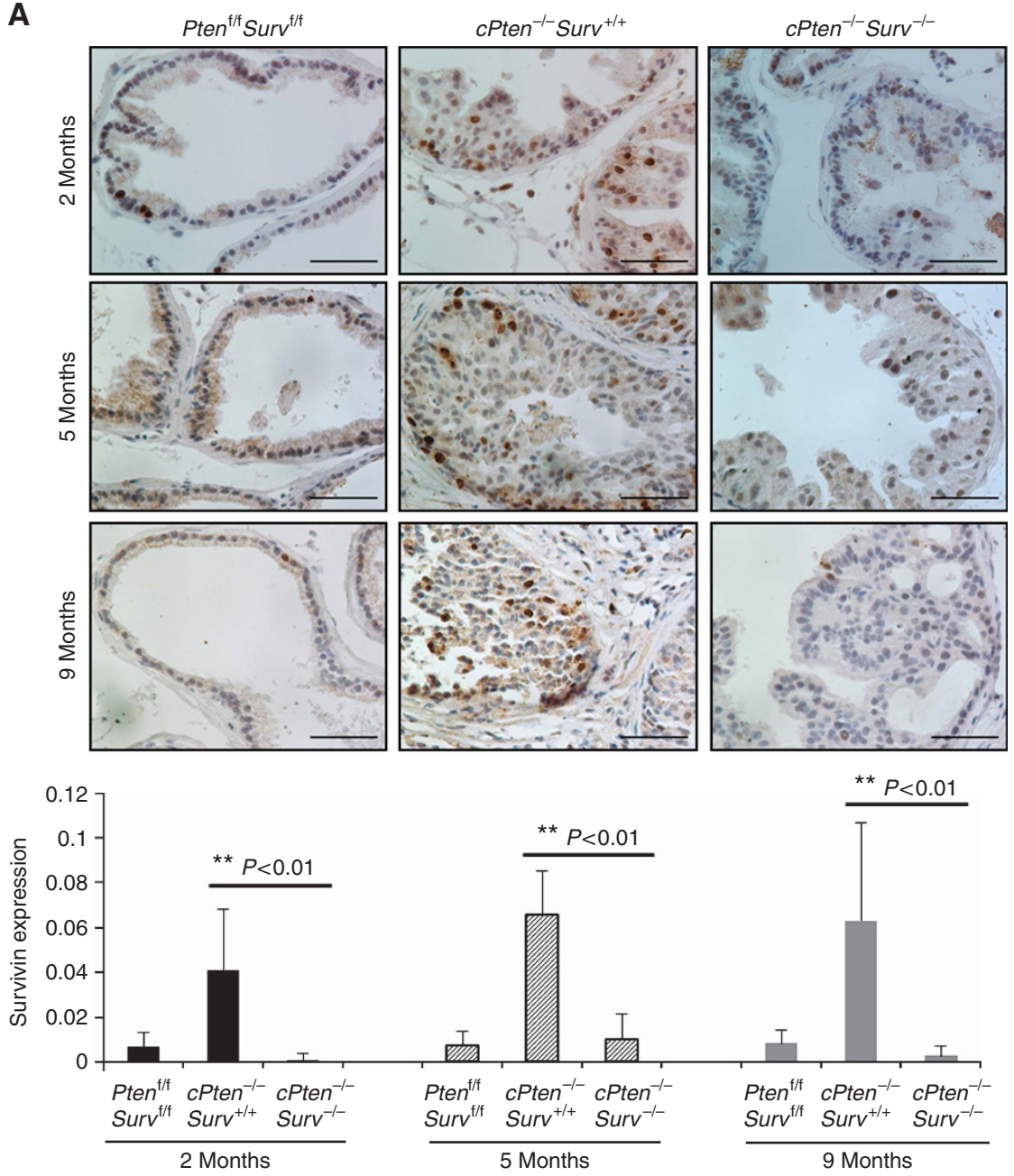

B
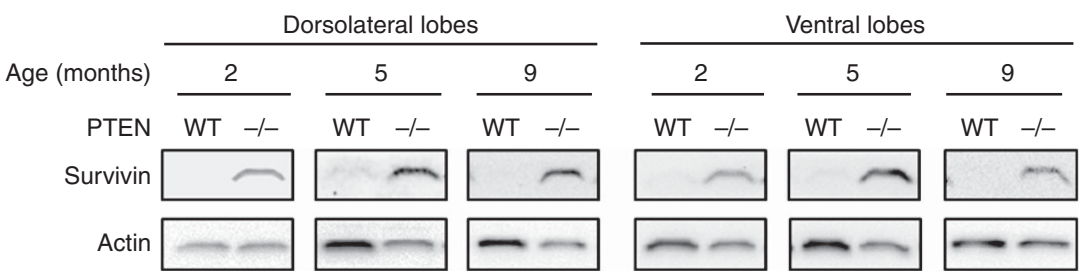

Figure 1. Survivin expression in mouse prostates. (A) Immunostaining of survivin on ventral prostate lobes of $P$ ten $n^{f / f} S^{f / f}, c P$ ten ${ }^{-/-} S^{+/+}$, and $c$ Pten ${ }^{-1-} S^{-1-}$ mice. At least three pictures were taken from each prostate section. Scale bars, $50 \mu \mathrm{m}$. ${ }^{\star \star} P<0.01$. (B) Survivin protein level in prostate tissues from $\operatorname{Pten}^{\mathrm{f} / \mathrm{f}} \mathrm{S}^{\mathrm{f} / \mathrm{f}}$ and $c \mathrm{Pten}^{-/-} \mathrm{S}^{+/+}$.

tissue from the conditional PTEN-deletion mice $\left(\right.$ cPten $\left.^{-/-} S^{+/+}\right)$ compared to that from wild-type $\left(\right.$ Pten $^{f / f} \mathcal{S}^{f / f}$ ) mice (Figure 1A; Supplementary Figure S1). A minimal level of survivin expression still seen in cPten $^{-1-}$ Surv $^{-1-}$ mice is probably attributed to the variable expression of Cre in the prostate tissue; cells lacking Cre resulted in incomplete deletion of survivin. The increase in survivin expression in both dorsolateral and ventral prostate lobes was observed as early as 2 months of age in hyperplastic tissue, but before prostate tumour development, and continued during tumour progression as shown at 5 and 9 months (Figure 1B). It is important to note that the mouse prostate dorsolateral lobe is most similar to the peripheral zone of the human prostate (Berquin et al, 2005), the site of origin for most cases of human PCa (Sakr and Grignon, 1998). These results indicate that loss of PTEN in the prostate results in a substantial upregulation of survivin expression that contributes to tumour development.
MAOA expression is upregulated in a survivin-dependent manner during PCa development. In our PCa model, MAOA protein was substantially upregulated in prostate tissues from the conditional PTEN-deletion mice ( Pten $^{-/}-S^{+/+}$) compared to that from wild-type mice (Pten ${ }^{f / f} \mathrm{~S}^{f / f}$ ) in both the dorsolateral and the ventral lobes (Figure 2A). Monoamine oxidase A is not expressed in normal prostate tissue but its expression remarkably increases with malignant progression from hyperplasia (2 months) to adenocarcinoma (13 months). In mice with conditional PTEN/ survivin double deletion in the prostate $\left(\right.$ cPten $\left.^{-/-} S^{-/-}\right)$, the MAOA protein level is reduced compared to that in $\mathrm{cPten}^{-1-} S^{+/+}$ indicating that the increase in MAOA is mediated at least in part by survivin. It is also important to note that survivin depletion delayed but not completely inhibited the upregulation of MAOA or tumour growth. In contrast to MAOA, MAOB is expressed in normal prostate tissue and its levels are substantially reduced in both dorsolateral and ventral lobes of prostate tissues from 
A

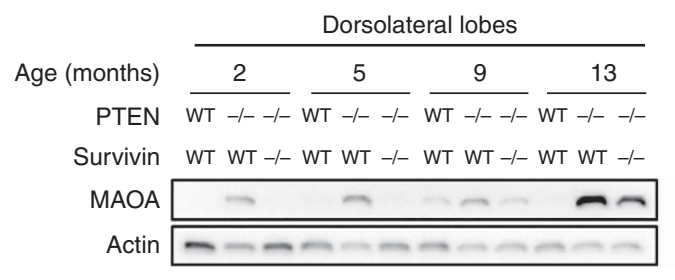

B

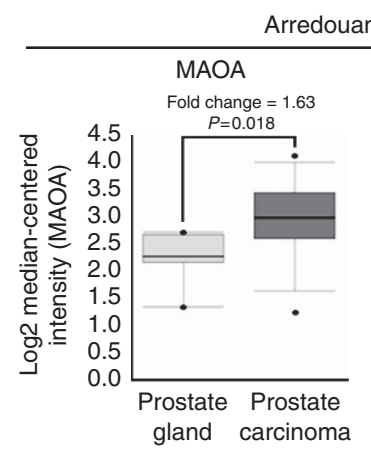

Dorsolateral lobes

Survivin
Fold change $=2.26$
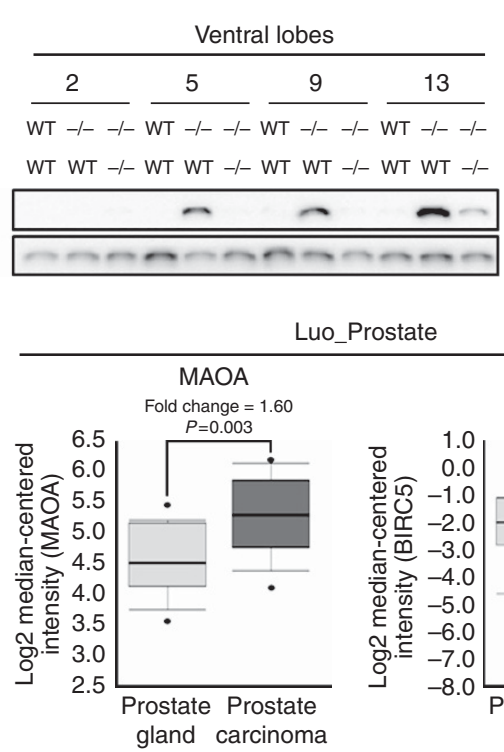

Luo_Prostate

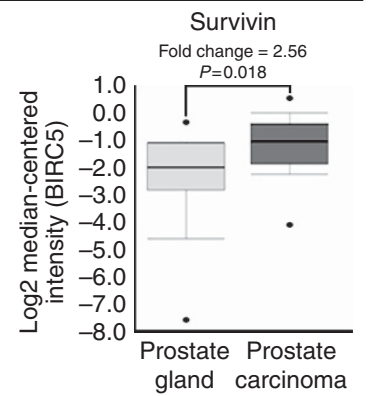

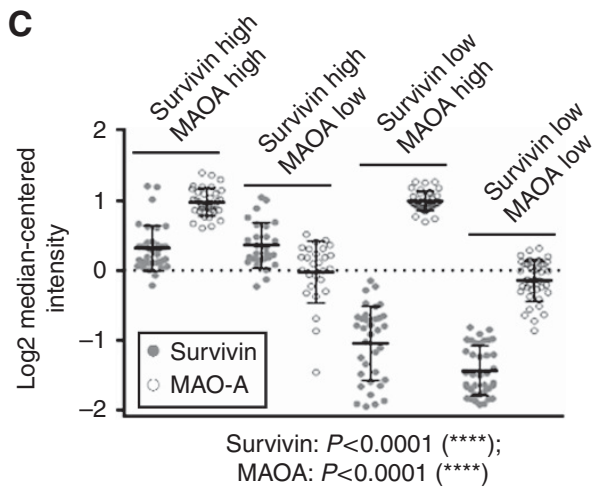

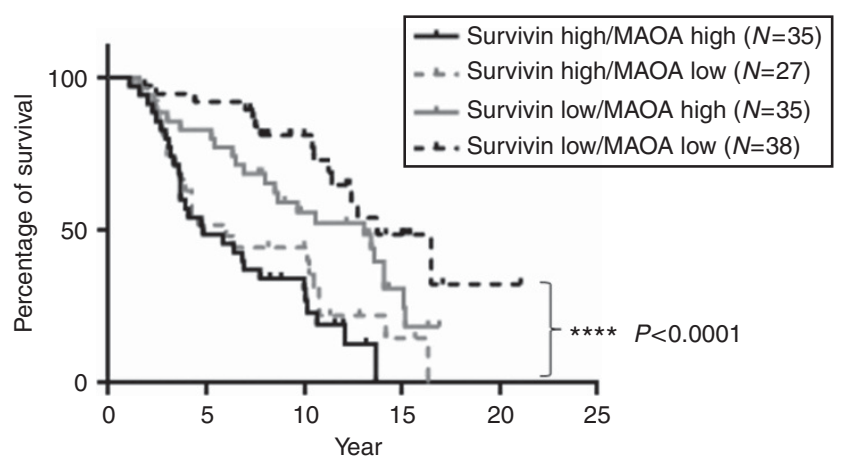

Figure 2. Overexpression of MAOA in PCa. (A) MAOA expression in mouse prostate from $P$ ten ${ }^{f / f} \mathrm{~S}^{f / f}$ and $c P$ ten ${ }^{-/-} \mathrm{S}^{+/+}$. (B) MAOA and survivin exhibit significantly higher levels in PCa compared to normal prostate gland tissue. Data were obtained from Oncomine and analysed using Prism 6 (GraphPad, Inc.; Luo et al, 2002; Arredouani et al, 2009). (C) Survival curves of PCa patients with different levels of survivin and MAOA in cancer tissues. Patient information (Setlur et al, 2008) was used for survival analysis. Four patient groups showed significant difference in survivin and MAOA expression based on one-way ANOVA multi-group analysis. The postoperative survival rate was analysed using Kaplan-Meier method. $\star \star \star \star P<0.0001$.

PTEN-deficient mice without correlation with the survivin status (WT and - / - ; Supplementary Figure S2A).

Consistent with our observations, both survivin and MAOA are significantly upregulated in human $\mathrm{PCa}$ compared to normal prostate gland tissue (Figure 2B; Supplementary Table S1), and there is no significantly different expression of MAOB between normal prostate gland and PCa tissue (Supplementary Figure S2B). We further grouped PCa patients based on survivin and MAOA expression in PCa. High expression of both survivin and MAOA was significantly associated with poor overall survival (Figure 2C). Together, these results corroborate the clinical significance of high survivin/MAOA expression in PCa development and progression.

Quinoxalinhydrazides suppress survivin expression. We designed and synthesised new active SC144 analogues SC186 and SC204, and an inactive analogue SC205 (Figure 3A). SC144, SC186 and SC204 substantially suppressed survivin expression after 24-h treatment in a panel of human PCa cells (LNCaP, DU145 and PC3) and mouse PTEN ${ }^{-1-}$ PCa cells (CE1, CE2 and E8 (Figure 3B). Among the three analogues, SC144 is the most potent survivin suppressant.

We further examined the effects of SC compounds on PCa cell growth. SC144 showed $\mathrm{IC}_{50}$ values of $<1 \mu \mathrm{M}$ in PCa cells (Table 1).
SC186 and SC204 were 5- to 10-fold less potent, and SC205 was inactive. Accordingly, SC144 showed highest potency in suppressing the colony-forming ability of PCa cells (Figure 3C). SC186 and SC204 showed moderate activity, whereas SC205 was inactive. These results are consistent with their activities in suppressing survivin expression. A previously reported survivin suppressant, YM155, also inhibited the growth of LNCaP and PC3 cells with $\mathrm{IC}_{50}$ values 15.2 and $3.2 \mathrm{~nm}$, respectively (Figure 3D).

Combined inhibition of survivin and MAOA is synergistic. To select a suitable in vitro model to study the combination of survivin and MAOA inhibition, we examined MAOA levels in four human PCa cell lines (LNCaP, PC3, DU145 and C4-2B; Figure 4A). Both LNCaP and C4-2B express high levels of MAOA, survivin and phosphorylated Akt, and undetectable level of PTEN; whereas PC3 and DU145 showed undetectable MAOA levels and low Akt phosphorylation. In addition, LNCaP cells exhibit the highest level of MAOA mRNA expression among the NCI-60 cell lines (Supplementary Figure S3). We further examined the regulatory relationship between MAOA and survivin. Silencing survivin had no significant effect on the protein level of MAOA, whereas silencing MAOA substantially decreased the protein level of survivin (Figure 4B). These data also suggest that in our survivin 
A<smiles>CC(C)CCn1ccnc1NC(=O)c1cccnc1</smiles><smiles>O=C(Nc1cnc2ccccc2n1)c1cnccn1</smiles>

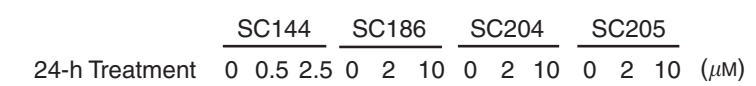

B

LNCaP $\quad$ Survivin

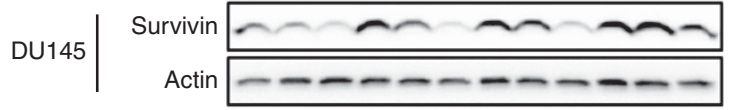

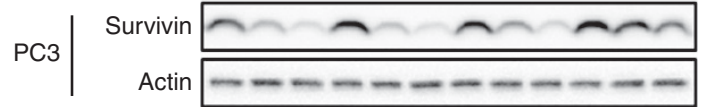

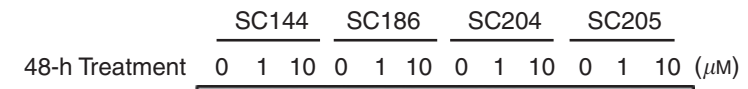

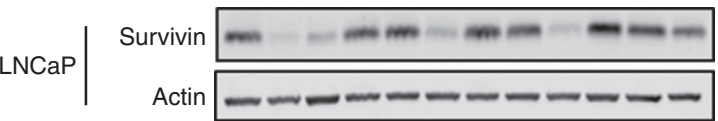

\section{LNCaP}
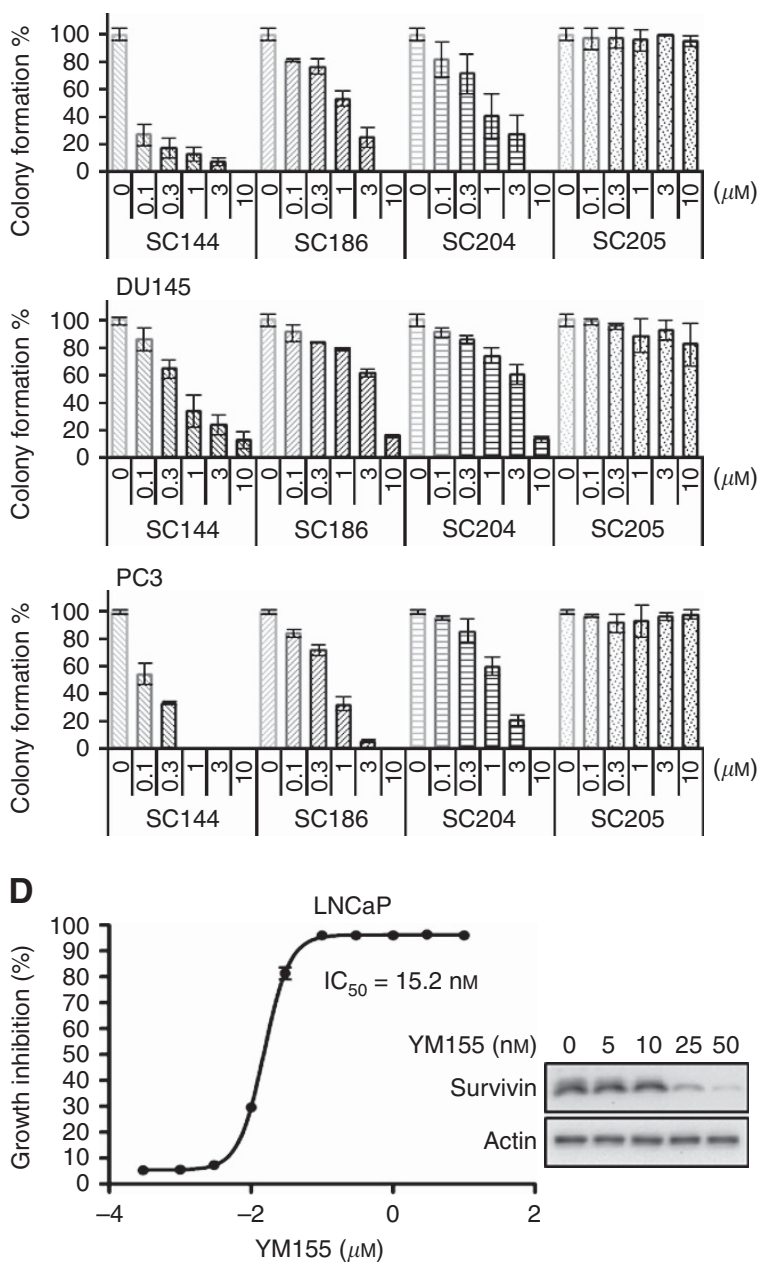
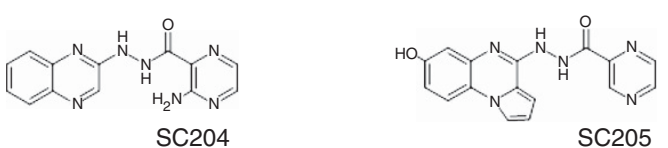
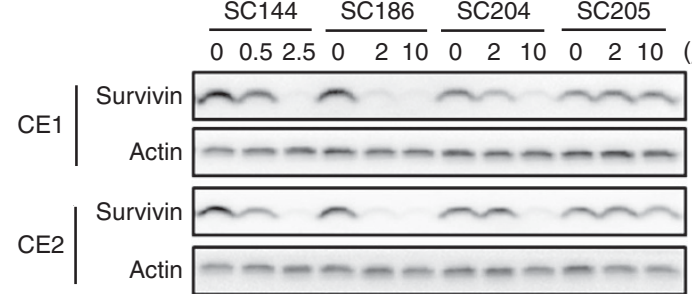

E8 $\begin{array}{r}\text { Survivin } \\ \text { Actin }\end{array}$ $(\mu \mathrm{M})$
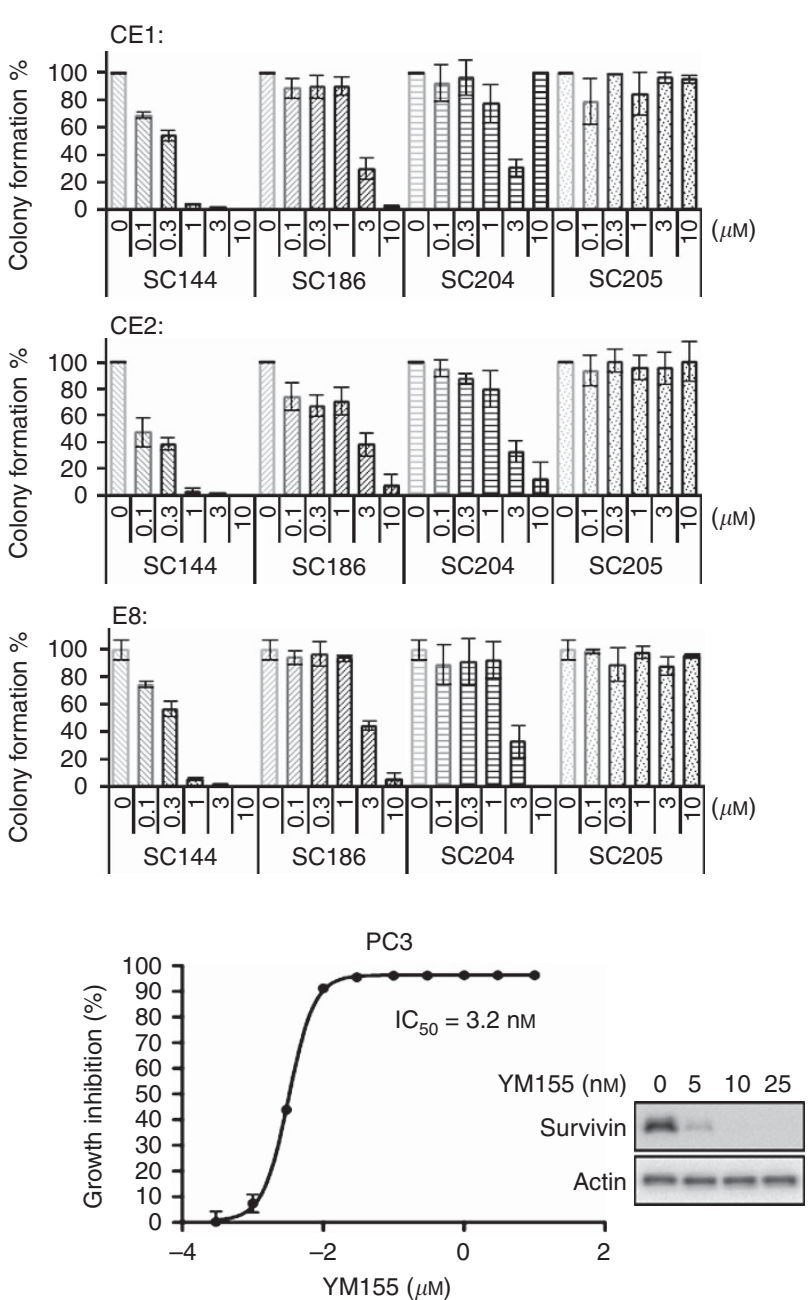

Figure 3. A novel class of survivin suppressants. (A) Chemical structures of SC144, SC186, SC204 and SC205. (B) Effects of SC144, SC186, SC204 and SC205 on survivin expression in human and mouse PCa cell lines. Human PCa cells LNCaP and PC3, and mouse PCa cells CE1, CE2 and E8 were treated with SC144, SC186, SC204 and SC205 for $24 \mathrm{~h}$ at the indicated concentrations before western blotting analysis. (C) Effects of SC144, SC186, SC204 and SC205 on the colony formation of PCa cells. Bars represent s.e.m. (D) Cytotoxicity of YM155 in LNCaP and PC3 cells. Inserted panels show the survivin-suppressing effect of 24-h YM155 treatment. 
Table 1. Toxicity of SC analogues in a panel of prostate cancer cells

\begin{tabular}{|c|c|c|c|c|c|c|c|c|}
\hline & \multicolumn{8}{|c|}{$\mathrm{IC}_{50}^{\mathrm{a}}(\mu \mathrm{M})$} \\
\hline & \multicolumn{3}{|c|}{ Human prostate cancer } & \multicolumn{5}{|c|}{ Mouse prostate cancer } \\
\hline & LNCaP & PC3 & DU145 & E2 & E4 & E8 & CE1 & CE2 \\
\hline PTEN & Negative & Negative & Positive & Negative & Negative & Negative & Negative & Negative \\
\hline Androgen & $A D^{b}$ & $A D I^{c}$ & $A D I$ & $A D$ & $A D$ & $A D$ & $A D I$ & ADI \\
\hline SC186 & $2.7 \pm 0.3^{d}$ & $0.54 \pm 0.03$ & $3.3 \pm 0.9$ & $2.0 \pm 0.1$ & $1.9 \pm 0.1$ & $2.2 \pm 0.1$ & $3.4 \pm 0.3$ & $4.0 \pm 0.1$ \\
\hline SC204 & $2.0 \pm 0.1$ & $0.64 \pm 0.03$ & $3.2 \pm 0.1$ & $1.3 \pm 0.1$ & $0.9 \pm 0.1$ & $2.0 \pm 0.1$ & $3.0 \pm 0.1$ & $2.1 \pm 0.1$ \\
\hline SC144 & $0.12 \pm 0.02$ & $0.09 \pm 0.01$ & $0.26 \pm 0.05$ & $0.29 \pm 0.01$ & $0.21 \pm 0.01$ & $0.60 \pm 0.01$ & $0.54 \pm 0.03$ & $0.59 \pm 0.01$ \\
\hline SC205 & $>10$ & $>10$ & $>10$ & $>10$ & $>10$ & $>10$ & $>10$ & $>10$ \\
\hline \multicolumn{9}{|c|}{ 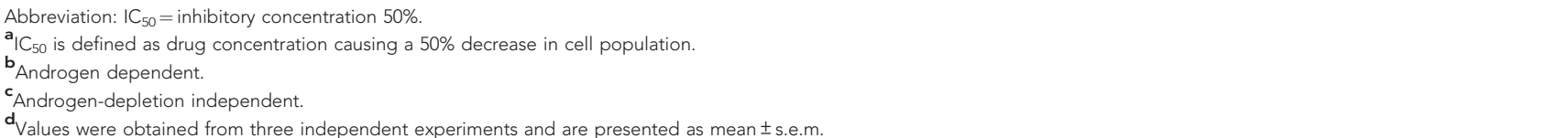 } \\
\hline
\end{tabular}

knockout animal model, the decreased MAOA expression might be due to indirect effects caused by the delayed tumour growth (Figure 2A).

Because LNCaP and C4-2B expressed highest levels of survivin and MAOA (Figure 4A), and $\mathrm{C} 4-2 \mathrm{~B}$ is a derivative cell line of $\mathrm{LNCaP}$, we selected LNCaP as an in vitro model to study the combined inhibition of MAOA and survivin. Like LNCaP, PC3 is also Pten deficient, but MAOA expression was undetectable and Akt phosphorylation was weak. Therefore, we selected PC3 as a negative-control cell line to test the combination.

SC144 at 0.05 and $0.1 \mu \mathrm{M}$ produced significant synergy when combined with $2 \mu \mathrm{M}$ clorgyline (a selective and irreversible MAOA inhibitor) in LNCaP (Figure 4C) but not in PC3 (Figure 4D). Clorgyline alone $(0.5,1$ and $2 \mu \mathrm{M})$ showed $<10 \%$ growth inhibition in both cell lines (Figure 4E and F). Consistently, clorgyline synergised with YM155 in LNCaP (Figure 4E) but not in PC3 (Figure 4F). We also examined the combinations of survivin suppressant and additional MAO inhibitors: phenelzine (an irreversible MAOA/B inhibitor), selegiline (an irreversible and selective MAOB inhibitor) and harmaline (a reversible and selective MAOA inhibitor). Similar to clorgyline, phenelzine and harmaline showed synergistic effects with SC144 or YM155, whereas the MAOB inhibitor selegiline did not show significant synergy (Figure 4G). Taken together, our results indicate that the combination of survivin/MAOA inhibitors yields synergistic enhancement of cytotoxicity in PCa cells with high survivin and MAOA levels.

We further compared the effects of SC144 as a single agent and in combination with clorgyline on suppressing survivin expression. In LNCaP cells, 48-h clorgyline treatment alone had no effects on survivin expression, whereas the combination of clorgyline and SC144 enhanced survivin suppression (Figure 4H), which is consistent with the results of siRNA (Figure 4B). In PC3 cells, the combination of clorgyline and SC144 did not show additive reduction in survivin expression. Taken together, these results indicate that MAOA plays a positive regulatory role on survivin expression and enhancement of survivin suppression is associated with the synergistic cytotoxicity of SC144 and YM155 with clorgyline.

Combination of survivin/MAOA inhibitors synergistically suppresses PCa cell migration. We further explored the association between survivin/MAOA expression and the metastatic status of PCa. Both survivin and MAOA are expressed at higher levels in metastatic PCa than primary site PCa (Figure 5A). We performed in vitro scratch assays to evaluate survivin/MAOA inhibition on PCa cell migration. In $\mathrm{LNCaP}$ cells, clorgyline alone had no substantial effect on cell migration, and SC144 alone exhibited moderate inhibition; whereas the combination of clorgyline and SC144 significantly impaired migration (Figure 5B). It is important to note that 72 -h drug treatments with SC144 $(0.5 \mu \mathrm{M})$ alone and in the combination of SC144 $(0.5 \mu \mathrm{M}) /$ clorgyline $(2 \mu \mathrm{M})$ caused 43 and $52 \%$ growth inhibition, respectively (Figure $4 \mathrm{C}$ ). However, in the cell migration assay (Figure 5B), 60-h drug treatments with SC144 $(0.5 \mu \mathrm{M})$ alone and in the combination of SC144 $(0.5 \mu \mathrm{M}) /$ clorgyline $(2 \mu \mathrm{M})$ caused 28 and $80 \%$ migration inhibition, respectively. In both assays, the effects of clorgyline alone were insignificant. These results show that the difference between single agents and drug combination was substantially larger in the migration assay compared to the cytotoxicity assay, indicating that the synergistic effect in the migration assay was mostly due to the inhibition of cell migration.

MMP-9, an important enzyme mediating cancer metastasis, was substantially decreased after SC144/clorgyline-combined treatment (Figure 5C). Owing to the significant role of MMP-9 in digesting the extracellular matrix for cancer cell invasion, we further performed a cell invasion assay. The combination of SC144 and clorgyline substantially reduced cell invasion compared to single agents or untreated control (Figure 5D). These results further support the clinical development of survivin suppressants in combination with MAOA inhibitors.

\section{DISCUSSION}

The rapid development of targeted therapeutic agents in oncology during the past decade has provided an unprecedented opportunity to study rational combination therapies (Kummar et al, 2010). Compared to single-agent treatment, drug combination has the potential to circumvent tumour resistance and yield synergy (DeVita et al, 1975; Chabner and Roberts, 2005). In this study, we reported a novel combination of survivin suppressants with MAOA inhibitors providing an alternative therapeutic strategy for $\mathrm{PCa}$ and an important insight into the cellular molecular network.

Although the regulatory pathways between survivin and MAOA remain elusive, survivin has been reported to regulate transcription factors. When complexed with HSP90, survivin inactivates the function of p53 (Kanwar et al, 2011; Millard et al, 2011). The acetylated form of survivin binds to the N-terminus of Stat3 and represses its transcriptional activity (Wang et al, 2010). On the basis of SABiosciences' proprietary database DECODE (Qiagen, Inc., Valencia, CA, USA), the promoter region of MAOA is potentially regulated by a large number of 
A

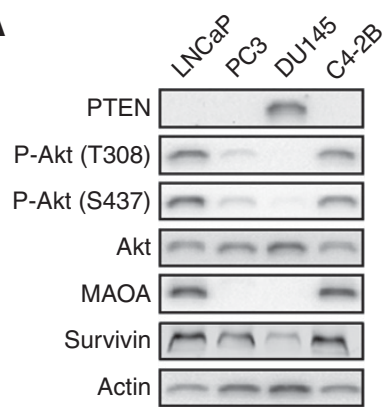

B
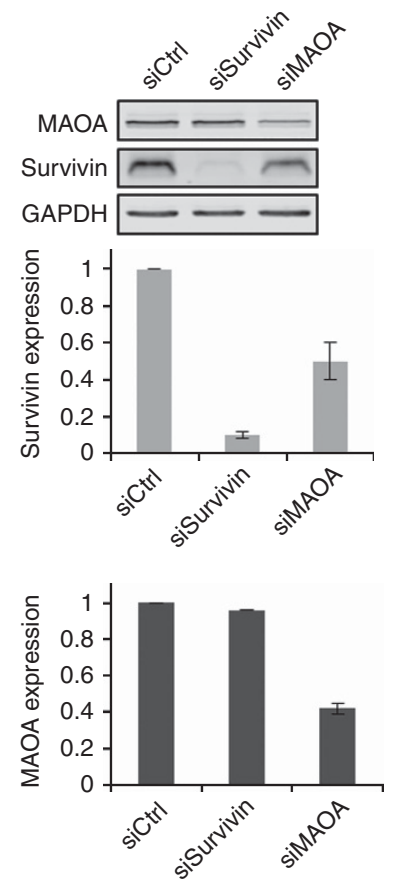

H

$\begin{array}{lllllllllll}\mathrm{SC} 144(\mu \mathrm{M}) & 0 & 0 & 0.05 & 0.05 & 0.1 & 0.1 & 0.5 & 0.5 & 1 & 1\end{array}$

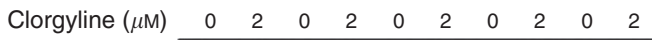

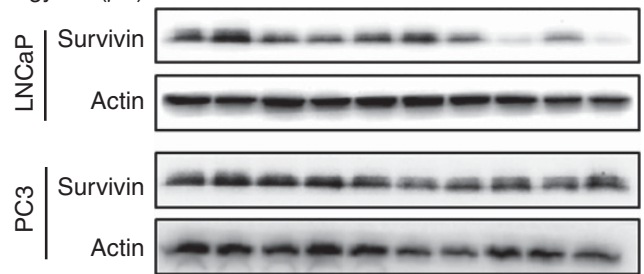

E
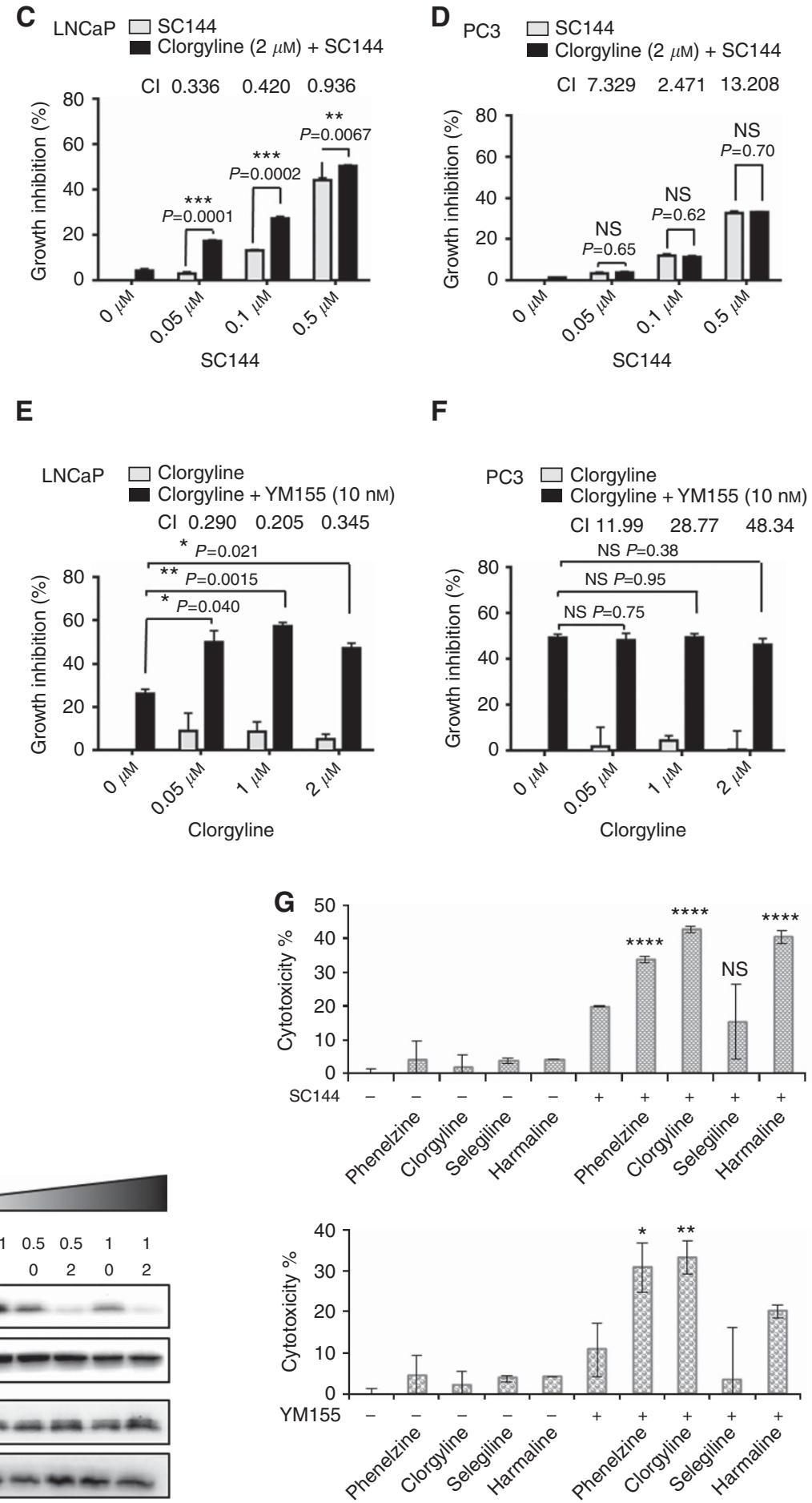

Figure 4. Inhibition of survivin and MAOA achieves synergistic cytotoxicity in LNCaP cells. (A) Expression of PTEN, phospho-Akt, Akt, MAOA and survivin in human PCa cells. (B) Effects of survivin and MAOA knockdown in LNCaP cells on the expression of MAOA and survivin, respectively. Combination of clorgyline and SC144 showed synergistic cytotoxicity in (C) LNCaP cells but not in (D) PC3 cells. Combination of clorgyline and YM155 showed synergistic cytotoxicity in (E) LNCaP cells but not in (F) PC3 cells. Cytotoxicity was measured by the MTT assay after 48-h drug treatment. Combination index (Cl) was calculated using Chou-Talalay method as described in Chen et al (2005). (G) Combinations of survivin suppressants and MAO inhibitors in LNCaP cells. Cells were pretreated with indicated MAO inhibitors at $2 \mu \mathrm{m}$ for $48 \mathrm{~h}$, prior to the combination of MAO inhibitors $(2 \mu \mathrm{M})$ and SC144 (0.1 $\mu \mathrm{m}$, upper panel) or YM155 (10 nM, lower panel) for another $72 \mathrm{~h}$. After drug treatment, growth inhibition was measured by the MTT assay. ${ }^{\star} P<0.05,{ }^{* \star} P<0.01$ and ${ }^{\star \star * \star} P<0.0001$. (H) Effects of combinational treatment with $\mathrm{SC} 144$ and clorgyline on survivin expression in LNCaP and PC3 cells. Cells were treated with SC144 and/or clorgyline for $48 \mathrm{~h}$, followed by western blotting analysis.

transcription factors, including GR, Sp1, AREB6, Egr-1, AP-1 and $\mathrm{c}$-Jun. These transcription factors may be directly or indirectly regulated by survivin.
A significant correlation was previously reported between increased MAOA expression and high Gleason grade or poorly differentiated human PCa (True et al, 2006; Peehl et al, 2008). 
A

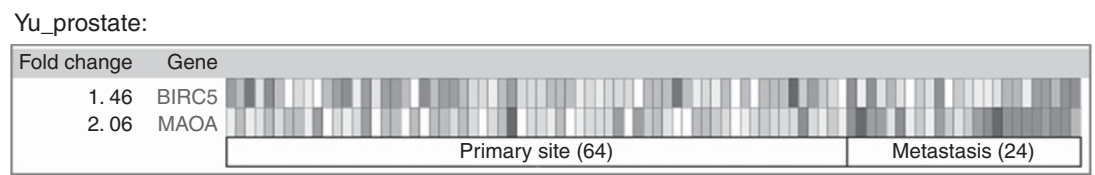

Least expressed Most expressed Correlation: $P<0.0001\left(^{\star \star \star *}\right)$

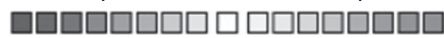
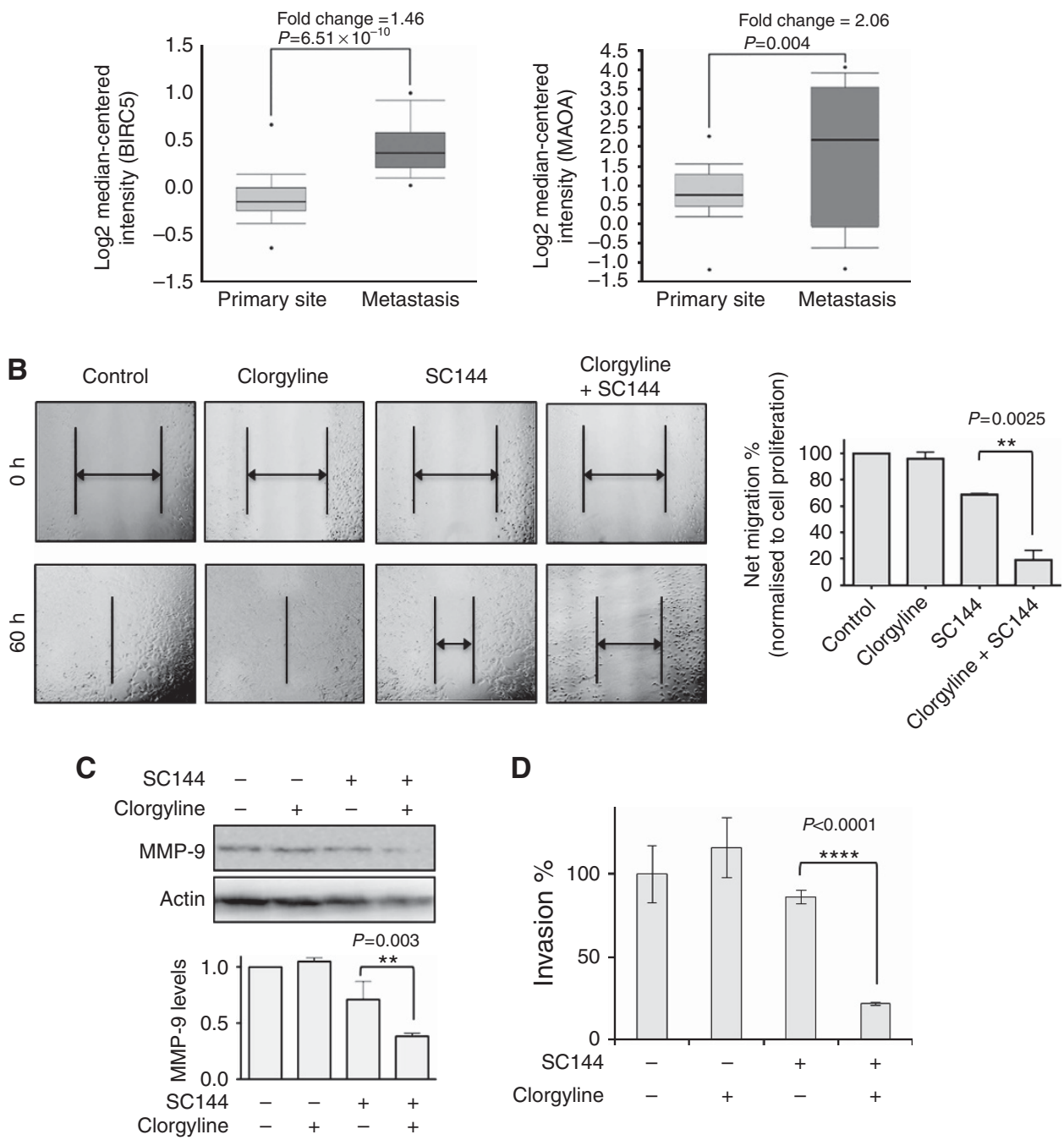

Figure 5. Inhibition of survivin and MAOA achieved synergistic inhibition of PCa cell migration. (A) MAOA and survivin exhibit significantly higher expression in metastatic PCa compared to primary site PCa. Oncomine was used for data analysis (Yu et al, 2004). Upper: heat map of MAOA and survivin expression in primary site and metastatic PCa. Lower: statistical analysis of MAOA and survivin (BIRC5) expression in primary site and metastatic PCa. (B) Effects of combination treatment with SC144 and clorgyline on cell migration. LNCaP cells were treated with $0.1 \mu \mathrm{M}$ SC144 or/and $2 \mu \mathrm{M}$ clorgyline. Left: one of three representative experiments is shown. Right: statistical analysis of the migration data. Bars represent s.e.m. $P=0.003$. (C) Effects of combination treatment with SC144 and clorgyline on MMP-9 expression in LNCaP cells. Cells were treated with $0.5 \mu \mathrm{M}$ SC144 and/or $2 \mu \mathrm{M}$ clorgyline for $48 \mathrm{~h}$, followed by western blotting analysis. Upper: one of two representative experiments is shown. Lower: statistical analysis of the western blotting data. Bars represent s.e.m. (D) Effects of SC144 $(0.5 \mu \mathrm{M}) /$ clorgyline $(\mu \mathrm{M})$ combination on LNCaP cell invasion through the Boyden chamber inserts coated with Matrigel. Bars represent s.e.m.

Consistent with the recent finding that increased MAOA expression in PCa promoted EMT (Wu et al, 2014), our data further showed that MMP-9 mediates MAOA-induced PCa metastasis. In addition, the evidence that both increased MAOA expression and the addition of 5-HT (Shinka et al, 2011) promoted PCa progression suggests that the direct and/or indirect metabolic products of MAOA contribute to PCa growth. Future studies will be needed to further elucidate the mechanisms.

The combination of MAOA inhibitors and survivin suppressants showed synergistic effect on decreasing the MMP-9 level. It is probably caused by the enhanced inhibition of survivin expression, because inhibition of survivin alone downregulated
MMP-9 expression, as is shown in Figure 5C and is supported by a recent study (Zhu et al, 2012). Increased MMP-9 expression is associated with androgen deprivation therapy and results in aggressive phenotype in PCa patients (Lin et al, 2013), further supporting the translational benefit of the above combination regime in PCa therapy.

Patient selection will be needed for effective therapeutic outcomes when using the combination of MAOA and survivin inhibitors. Our novel combination treatment would be most effective in PCa patients with high levels of MAOA and survivin expression in their tumour tissues. Before clinical test of this therapeutic combination, further preclinical follow-up studies are 
needed to optimise the ratio of the two drugs and the treatment schedule in in vivo PCa models.

\section{ACKNOWLEDGEMENTS}

The authors would like to thank Ms. Hetian Chen for assistance with multiple experiments.

\section{REFERENCES}

Adisetiyo H, Liang M, Liao CP, Aycock-Williams A, Cohen MB, Xu S, Neamati N, Conway EM, Cheng CY, Nikitin AY, Roy-Burman P (2013) Loss of survivin in the prostate epithelium impedes carcinogenesis in a mouse model of prostate adenocarcinoma. PLoS One 8(7): e69484.

Altieri DC (2008) Survivin, cancer networks and pathway-directed drug discovery. Nat Rev Cancer 8(1): 61-70.

Altieri DC, Languino LR, Lian JB, Stein JL, Leav I, van Wijnen AJ, Jiang Z, Stein GS (2009) Prostate cancer regulatory networks. J Cell Biochem 107(5): 845-852.

Arredouani MS, Lu B, Bhasin M, Eljanne M, Yue W, Mosquera JM, Bubley GJ, Li V, Rubin MA, Libermann TA, Sanda MG (2009) Identification of the transcription factor single-minded homologue 2 as a potential biomarker and immunotherapy target in prostate cancer. Clin Cancer Res 15(18): 5794-5802.

Berquin IM, Min Y, Wu R, Wu H, Chen YQ (2005) Expression signature of the mouse prostate. J Biol Chem 280(43): 36442-36451.

Chabner BA, Roberts Jr TG (2005) Timeline: chemotherapy and the war on cancer. Nat Rev Cancer 5(1): 65-72.

Chen X, Plasencia C, Hou Y, Neamati N (2005) Synthesis and biological evaluation of dimeric RGD peptide-paclitaxel conjugate as a model for integrin-targeted drug delivery. J Med Chem 48(4): 1098-1106.

Church DN, Talbot DC (2012) Survivin in solid tumors: rationale for development of inhibitors. Curr Oncol Rep 14(2): 120-128.

Debnath B, Xu S, Neamati N (2012) Small molecule inhibitors of signal transducer and activator of transcription 3 (Stat3) protein. J Med Chem 55(15): 6645-6668.

DeVita Jr VT, Young RC, Canellos GP (1975) Combination versus single agent chemotherapy: a review of the basis for selection of drug treatment of cancer. Cancer 35(1): 98-110.

Flamand V, Zhao H, Peehl DM (2010) Targeting monoamine oxidase A in advanced prostate cancer. J Cancer Res Clin Oncol 136(11): 1761-1771.

Grande F, Aiello F, Grazia OD, Brizzi A, Garofalo A, Neamati N (2007) Synthesis and antitumor activities of a series of novel quinoxalinhydrazides. Bioorg Med Chem 15(1): 288-294.

Grande F, Yamada R, Cao X, Aiello F, Garofalo A, Neamati N (2009) Synthesis and biological evaluation of novel hydrazide based cytotoxic agents. Expert Opin Investig Drugs 18(5): 555-568.

Gray IC, Stewart LM, Phillips SM, Hamilton JA, Gray NE, Watson GJ, Spurr NK, Snary D (1998) Mutation and expression analysis of the putative prostate tumour-suppressor gene PTEN. Br J Cancer 78(10): $1296-1300$.

Kanwar JR, Kamalapuram SK, Kanwar RK (2011) Targeting survivin in cancer: the cell-signalling perspective. Drug Discov Today 16(11-12): 485-494.

Kummar S, Chen HX, Wright J, Holbeck S, Millin MD, Tomaszewski J, Zweibel J, Collins J, Doroshow JH (2010) Utilizing targeted cancer therapeutic agents in combination: novel approaches and urgent requirements. Nat Rev Drug Discov 9(11): 843-856.

Lin TH, Lee SO, Niu Y, Xu D, Liang L, Li L, Yeh SD, Fujimoto N, Yeh S, Chang C (2013) Differential androgen deprivation therapies with anti-androgens casodex/bicalutamide or MDV3100/enzalutamide versus anti-androgen receptor ASC-J9(R) lead to promotion versus suppression of prostate cancer metastasis. J Biol Chem 288(27): 19359-19369.

Luo JH, Yu YP, Cieply K, Lin F, Deflavia P, Dhir R, Finkelstein S, Michalopoulos G, Becich M (2002) Gene expression analysis of prostate cancers. Mol Carcinog 33(1): 25-35.

Millard M, Pathania D, Grande F, Xu S, Neamati N (2011) Small-molecule inhibitors of p53-MDM2 interaction: the 2006-2010 update. Curr Pharm Des 17(6): 536-559.
Nakahara T, Kita A, Yamanaka K, Mori M, Amino N, Takeuchi M, Tominaga F, Hatakeyama S, Kinoyama I, Matsuhisa A, Kudoh M, Sasamata M (2007) YM155, a novel small-molecule survivin suppressant, induces regression of established human hormone-refractory prostate tumor xenografts. Cancer Res 67(17): 8014-8021.

Oshima T, Cao X, Grande F, Yamada R, Garofalo A, Louie S, Neamati N (2009) Combination effects of SC144 and cytotoxic anticancer agents. Anticancer Drugs 20(5): 312-320.

Peehl DM, Coram M, Khine H, Reese S, Nolley R, Zhao H (2008) The significance of monoamine oxidase-A expression in high grade prostate cancer. J Urol 180(5): 2206-2211.

Pietrangeli P, Mondovi B (2004) Amine oxidases and tumors. Neurotoxicology 25(1-2): 317-324.

Sah NK, Khan Z, Khan GJ, Bisen PS (2006) Structural, functional and therapeutic biology of survivin. Cancer Lett 244(2): 164-171.

Saha S, Reddy ChV, Xu S, Sankar S, Neamati N, Patro B (2013) Synthesis and SAR studies of marine natural products ma'edamines A, B and their analogues. Bioorg Med Chem Lett 23(18): 5135-5139.

Sakr WA, Grignon DJ (1998) Prostatic intraepithelial neoplasia and atypical adenomatous hyperplasia. Relationship to pathologic parameters, volume and spatial distribution of carcinoma of the prostate. Anal Quant Cytol Histol 20(5): 417-423.

Setlur SR, Mertz KD, Hoshida Y, Demichelis F, Lupien M, Perner S, Sboner A, Pawitan Y, Andren O, Johnson LA, Tang J, Adami HO, Calza S, Chinnaiyan AM, Rhodes D, Tomlins S, Fall K, Mucci LA, Kantoff PW, Stampfer MJ, Andersson SO, Varenhorst E, Johansson JE, Brown M, Golub TR, Rubin MA (2008) Estrogen-dependent signaling in a molecularly distinct subclass of aggressive prostate cancer. J Natl Cancer Inst 100(11): 815-825.

Shih JC, Chen K, Ridd MJ (1999) Monoamine oxidase: from genes to behavior. Annu Rev Neurosci 22: 197-217.

Shinka T, Onodera D, Tanaka T, Shoji N, Miyazaki T, Moriuchi T, Fukumoto T (2011) Serotonin synthesis and metabolism-related molecules in a human prostate cancer cell line. Oncol Lett 2(2): 211-215.

Tolcher AW, Quinn DI, Ferrari A, Ahmann F, Giaccone G, Drake T, Keating A, de Bono JS (2012) A phase II study of YM155, a novel small-molecule suppressor of survivin, in castration-resistant taxanepretreated prostate cancer. Ann Oncol 23(4): 968-973.

Trotman LC, Niki M, Dotan ZA, Koutcher JA, Di Cristofano A, Xiao A, Khoo AS, Roy-Burman P, Greenberg NM, Van Dyke T, Cordon-Cardo C, Pandolfi PP (2003) Pten dose dictates cancer progression in the prostate. PLoS Biol 1(3): E59.

True L, Coleman I, Hawley S, Huang CY, Gifford D, Coleman R, Beer TM, Gelmann E, Datta M, Mostaghel E, Knudsen B, Lange P, Vessella R, Lin D, Hood L, Nelson PS (2006) A molecular correlate to the Gleason grading system for prostate adenocarcinoma. Proc Natl Acad Sci USA 103(29): 10991-10996.

Vaarala MH, Porvari K, Kyllonen A, Vihko P (2000) Differentially expressed genes in two LNCaP prostate cancer cell lines reflecting changes during prostate cancer progression. Lab Invest 80(8): 1259-1268.

Velculescu VE, Madden SL, Zhang L, Lash AE, Yu J, Rago C, Lal A, Wang CJ, Beaudry GA, Ciriello KM, Cook BP, Dufault MR, Ferguson AT, Gao Y, He TC, Hermeking H, Hiraldo SK, Hwang PM, Lopez MA, Luderer HF, Mathews B, Petroziello JM, Polyak K, Zawel L, Kinzler KW et al. (1999) Analysis of human transcriptomes. Nat Genet 23(4): 387-388.

Wang H, Holloway MP, Ma L, Cooper ZA, Riolo M, Samkari A, Elenitoba-Johnson KS, Chin YE, Altura RA (2010) Acetylation directs survivin nuclear localization to repress STAT3 oncogenic activity. J Biol Chem 285(46): 36129-36137.

Wang S, Gao J, Lei Q, Rozengurt N, Pritchard C, Jiao J, Thomas GV, Li G, Roy-Burman P, Nelson PS, Liu X, Wu H (2003) Prostate-specific deletion of the murine Pten tumor suppressor gene leads to metastatic prostate cancer. Cancer Cell 4(3): 209-221.

Wei Z, Satram-Maharaj T, Chaharyn B, Kuski K, Pennington PR, Cao X, Chlan J, Mousseau DD (2012) Aspartic acid substitutions in monoamine oxidase-A reveal both catalytic-dependent and -independent influences on cell viability and proliferation. J Neural Transm 119(11): 1285-1294.

Wendt MD, Sun C, Kunzer A, Sauer D, Sarris K, Hoff E, Yu L, Nettesheim DG, Chen J, Jin S, Comess KM, Fan Y, Anderson SN, Isaac B, Olejniczak ET, Hajduk PJ, Rosenberg SH, Elmore SW (2007) Discovery of a novel small molecule binding site of human survivin. Bioorg Med Chem Lett 17(11): 3122-3129. 
White TA, Kwon EM, Fu R, Lucas JM, Ostrander EA, Stanford JL, Nelson PS (2012) The monoamine oxidase A gene promoter repeat and prostate cancer risk. Prostate 72(15): 1622-1627.

Workman P, Aboagye EO, Balkwill F, Balmain A, Bruder G, Chaplin DJ, Double JA, Everitt J, Farningham DA, Glennie MJ, Kelland LR, Robinson V, Stratford IJ, Tozer GM, Watson S, Wedge SR, Eccles SA. Committee of the National Cancer Research I (2010) Guidelines for the welfare and use of animals in cancer research. Br J Cancer 102(11): 1555-1577.

Wu JB, Shao C, Li X, Li Q, Hu P, Shi C, Li Y, Chen YT, Yin F, Liao CP, Stiles BL, Zhau HE, Shih JC, Chung LW (2014) Monoamine oxidase A mediates prostate tumorigenesis and cancer metastasis. J Clin Invest 124(7): 2891-2908.

Xu S, Butkevich AN, Yamada R, Zhou Y, Debnath B, Duncan R, Zandi E, Petasis NA, Neamati N (2012) Discovery of an orally active small-molecule irreversible inhibitor of protein disulfide isomerase for ovarian cancer treatment. Proc Natl Acad Sci USA 109(40): 16348-16353.

Xu S, Grande F, Garofalo A, Neamati N (2013a) Discovery of a novel orally active small-molecule gp130 inhibitor for the treatment of ovarian cancer. Mol Cancer Ther 12(6): 937-949.

Xu S, Neamati N (2013) gp130: a promising drug target for cancer therapy. Expert Opin Ther Targets 17(11): 1303-1328.

Xu S, Oshima T, Imada T, Masuda M, Debnath B, Grande F, Garofalo A, Neamati N (2013b) Stabilization of MDA-7/IL-24 for colon cancer therapy. Cancer Lett 335(2): 421-430.

Yamada R, Kostova MB, Anchoori RK, Xu S, Neamati N, Khan SR (2010) Biological evaluation of paclitaxel-peptide conjugates as a model for MMP2-targeted drug delivery. Cancer Biol Ther 9(3): 192-203.
Youdim MB, Edmondson D, Tipton KF (2006) The therapeutic potential of monoamine oxidase inhibitors. Nat Rev Neurosci 7(4): 295-309.

Yu YP, Landsittel D, Jing L, Nelson J, Ren B, Liu L, McDonald C, Thomas R, Dhir R, Finkelstein S, Michalopoulos G, Becich M, Luo JH (2004) Gene expression alterations in prostate cancer predicting tumor aggression and preceding development of malignancy. J Clin Oncol 22(14): 2790-2799.

Zeng LF, Wang Y, Kazemi R, Xu S, Xu ZL, Sanchez TW, Yang LM, Debnath B, Odde S, Xie H, Zheng YT, Ding J, Neamati N, Long YQ (2012) Repositioning HIV-1 integrase inhibitors for cancer therapeutics: 1,6-naphthyridine-7-carboxamide as a promising scaffold with drug-like properties. J Med Chem 55(22): 9492-9509.

Zhao H, Flamand V, Peehl DM (2009) Anti-oncogenic and pro-differentiation effects of clorgyline, a monoamine oxidase A inhibitor, on high grade prostate cancer cells. BMC Med Genomics 2: 55.

Zhao H, Nolley R, Chen Z, Reese SW, Peehl DM (2008) Inhibition of monoamine oxidase A promotes secretory differentiation in basal prostatic epithelial cells. Differentiation 76(7): 820-830.

Zhu J, Lu X, Hua KQ, Sun H, Yu YH, Feng YJ (2012) Oestrogen receptor alpha mediates 17beta-estradiol enhancement of ovarian cancer cell motility through up-regulation of survivin expression. Arch Gynecol Obstet 286(3): 729-737.

This work is published under the standard license to publish agreement. After 12 months the work will become freely available and the license terms will switch to a Creative Commons AttributionNonCommercial-Share Alike 4.0 Unported License

Supplementary Information accompanies this paper on British Journal of Cancer website (http://www.nature.com/bjc) 